\title{
The effects of memory set size and information structure on learning and retention
}

\author{
James A. Kole And Alice F. Healy \\ University of Colorado, Boulder, Colorado
}

\begin{abstract}
Two experiments examined the effects of memory set size and information structure on learning and retention. Participants learned 48 (small set) or 144 (large set) facts about individuals, and were tested over 48 facts. The test facts included either 4 facts about 12 individuals (12-person condition) or 12 facts about 4 individuals (4-person condition). During learning, there was an advantage for the small-set group in the 4-person condition, but a disadvantage in the 12-person condition. During testing, there was an advantage for the 4-person condition relative to the 12-person condition for the small-set group, even when the conditions were equated in terms of name exposure. The results support a mental model account of memory representation and retrieval.
\end{abstract}

This study investigates how memory set size and information structure affect learning and retention, using materials employed earlier by Van Overschelde and Healy (2001) to study learning under conditions of information overload. Participants in the present study learned either 48 or 144 facts about individuals, designated as small set and large set, respectively. Participants in the small-set group learned either 12 facts about each of 4 individuals or 4 facts about each of 12 individuals, whereas participants in the large-set group learned 12 facts about each of 12 individuals. Participants were then tested on either 12 facts about each of 4 individuals (4-person condition) or 4 facts about each of 12 individuals (12-person condition).

Although the effect of memory set size is well understood (e.g., Ward, 2002), the effect of information structure is not easily predicted; different theoretical accounts make different predictions. Here we focus on two accounts, propositional networks and mental models. These accounts have been compared by Sohn, Anderson, Reder, and Goode (2004), who used the standard fan-effect paradigm (e.g., Anderson, 1974) and varied attentional focus during learning. They found support for the propositional network account (but see Radvansky, 2005).

\section{Propositional Networks}

In propositional networks, concepts are represented as nodes, and relationships between concepts as links between nodes (Anderson, 1983). Learning is the formation of a link between two nodes. In retrieving information, a memory probe activates a node, and this activation is transferred along all the links connected to that node (i.e., spreading activation). As the number of links to a node increases, less activation is transferred along each link. The attenuation of transferred activation results in decreased performance in terms of speed or accuracy (the fan effect).
A propositional network account would predict an advantage for the 12-person small-set group in the present study. This prediction follows from the fact that in the 12-person small-set group, participants learn 4 facts about 12 individuals, thus activation would spread along only 4 links associated with each person node. In all other groups, participants learn 12 facts about each individual, thus activation would spread along 12 links associated with each node.

\section{Mental Models}

Radvansky (2005; Radvansky \& Zacks, 1991) offers a different account of the fan effect based on mental models (Johnson-Laird, 1983) or situation models (van Dijk \& Kintsch, 1983). He argues that when learning new information, a mental model is constructed. For example, if learning facts about individuals, each individual is represented by a different mental model, and facts about an individual are integrated into the appropriate mental model. Mental models are stored in long-term memory; so retrieving information is a two-step process in which the appropriate mental model is retrieved from long-term to working memory, and the contents of the mental model are examined within working memory.

There are three assumptions of this retrieval process: First, as the number of mental models increases, interference in retrieving a specific mental model from long-term memory increases (i.e., intermodel interference), leading to a fan effect. Second, as the number of facts within a mental model increases, interference in retrieving a specific fact increases (i.e., intramodel interference), creating a second, lower level fan effect. Third, intermodel interference is larger than intramodel interference (Radvansky \& Zacks, 1991).

A mental model account would predict an advantage for the 4-person small-set group because in this group only 4 mental models are constructed, one for each individual in 
the learning set. In the other three conditions, 12 mental models are constructed because there are 12 individuals in the learning set. Furthermore, performance for the 12person small-set group should be better than that for the 12-person large-set and 4-person large-set groups. Presumably, each of these three groups requires creating 12 mental models; however, there are only 4 items within each model in the 12-person small-set group, as opposed to 12 in the large-set groups.

These predictions are based on the assumption that participants form person-based mental models. It is possible that they form instead fact-category-based mental models. However, this possibility seems unlikely for two reasons. First, as in the person-focus condition of the study by Sohn et al. (2004), participants received person-anchored questions in the present study. Second, to strengthen the person focus, in Experiment 2 participants were explicitly instructed to organize facts around each person.

\section{EXPERIMENT 1}

\section{Method}

\section{Participants}

Fifty-six University of Colorado undergraduates participated. All were native English speakers.

\section{Design}

The design of the learning phase was a $2 \times 2 \times 3$ mixed factorial, with the first two factors manipulated between subjects. The first variable was set-size group. Participants learned 48 facts in the small-set group, and 144 facts in the large-set group. The second variable was test condition. For the small-set group, in the 12-person condition participants learned and were tested on 4 facts about each of 12 individuals, and in the 4-person condition participants learned and were tested on 12 facts about each of 4 individuals. For the large-set group, all participants learned 12 facts about each of 12 individuals. They differed only on the test, not learning. For the 12person condition, they were tested on only 4 facts about each individual, whereas for the 4-person condition, they were tested on 12 facts about only 4 individuals (see Table 1 ). Thus, the variable of test condition should affect learning only for the small-set group. The remaining factor was learning round (1-3).

The design of the test phase included only the variables set-size group and test condition. Both proportion of correct responses and time to initiate correct responses were analyzed.

\section{Materials}

A set of 144 fictitious facts was adopted from Van Overschelde and Healy (2001); 12 unique facts were associated with each of 12 individuals, with 1 fact per fact category. The facts were presented as sentences, each including individual, verb phrase, and fact category exemplar in that order (e.g., Barbara Fontana has a pet retriever). The 12 verb phrases were each associated with one of the fact categories

Table 1

Summary of the Method Used in Experiments 1 and 2

\begin{tabular}{lcccccc}
\hline & \multicolumn{2}{c}{ Large Set } & & \multicolumn{2}{c}{ Small Set } \\
\cline { 2 - 3 } \cline { 5 - 6 } \multicolumn{1}{c}{ Number of . . } & 4-Person & 12-Person & & 4-Person & 12-Person \\
\hline Facts learned & 144 & 144 & & 48 & 48 \\
People learned & 12 & 12 & & 4 & 12 \\
Facts learned per person & 12 & 12 & & 12 & 4 \\
Facts tested & 48 & 48 & & 48 & 48 \\
People tested & 4 & 12 & & 4 & 12 \\
Facts tested per person & 12 & 4 & & 12 & 4 \\
\hline
\end{tabular}

and varied from 1 to 4 words. The fact categories were commonly known attributes about individuals, such as favorite author and favorite food. Each fact category exemplar was a one-word common instance of the fact category (see the Appendix). Note that, unlike typical fan-effect experiments (Anderson, 1974), fact categories, but not fact category exemplars, were repeated across individuals.

\section{Procedure}

Participants were tested individually on Apple I-Mac computers.

Learning. During learning, each fact was shown individually for $2.5 \mathrm{sec}$, in blocks of 12 facts. For the large-set group, 1 fact was presented about each of the 12 individuals, and each of the 12 fact categories was used 1 time. In the 12-person small-set group, 1 fact was presented about each of the 12 individuals, and each of 4 fact categories was used 3 times. In the 4-person small-set group, 3 facts were presented about each of 4 individuals, and each of the 12 fact categories was used 1 time. After each block was a cued recall test over the facts presented within the block. Participants were given a name and a verb phrase, and they were to provide the fact category exemplar. The ordering of cues during the cued recall test was the same as the ordering of facts during fact presentation. Participants were given $8 \mathrm{sec}$ to initiate a typing response before the program advanced to the next question. The presentation and testing of the 144 (large-set group) or 48 (small-set group) facts constituted one learning round, and participants completed three learning rounds. For each learning round, the same 12 facts occurred together within each block; however, both the order of facts within each block and the order of blocks were randomized.

Test. Immediately following learning, all participants were given a cued recall test over 48 facts presented in a pseudorandom order. Cues were grouped as for the small-set group but in a different order.

\section{Results}

\section{Learning}

Accuracy. During learning, only 12 facts were studied and then tested in a given block for both set-size groups. Overall accuracy was better for the 4-person than for the 12-person conditions $\left[F(1,44)=32.94, M S_{\mathrm{e}}=.041\right.$, $p<.01]$. However, in the 4-person condition, accuracy was better for the small-set than for the large-set group, whereas the 12-person condition showed the opposite pattern. Thus, test condition interacted with set-size group $\left[F(1,44)=25.79, M S_{\mathrm{e}}=.041, p<.01\right]$. Alternatively, this interaction indicates that the disadvantage for the 12person condition was found only for the small-set group, presumably because there was no difference in procedure between the two test conditions during learning in the large-set group.

In the small-set group, performance increased monotonically across learning rounds, whereas in the large-set group, despite the repeated study, performance decreased monotonically (Figure 1), as in previous studies (Kole \& Healy, 2007; Van Overschelde \& Healy, 2001); learning round interacted with set-size group $[F(2,88)=21.64$, $\left.M S_{\mathrm{e}}=.005, p<.01\right]$.

Initiation time. Initiation time improved across learning rounds $\left[F(2,88)=13.37, M S_{\mathrm{e}}=.003, p<.01\right]$. This improvement was more dramatic for the large-set than for the small-set group (Figure 2); the interaction of learning round and set-size group was significant $[F(2,88)=3.73$, $\left.M S_{\mathrm{e}}=.003, p=.03\right]$. Participants were faster overall in the large-set than in the small-set group $[F(1,44)=4.88$, $\left.M S_{\mathrm{e}}=.021, p=.03\right]$. This advantage for the large-set group was evident only for the 12-person condition; the 


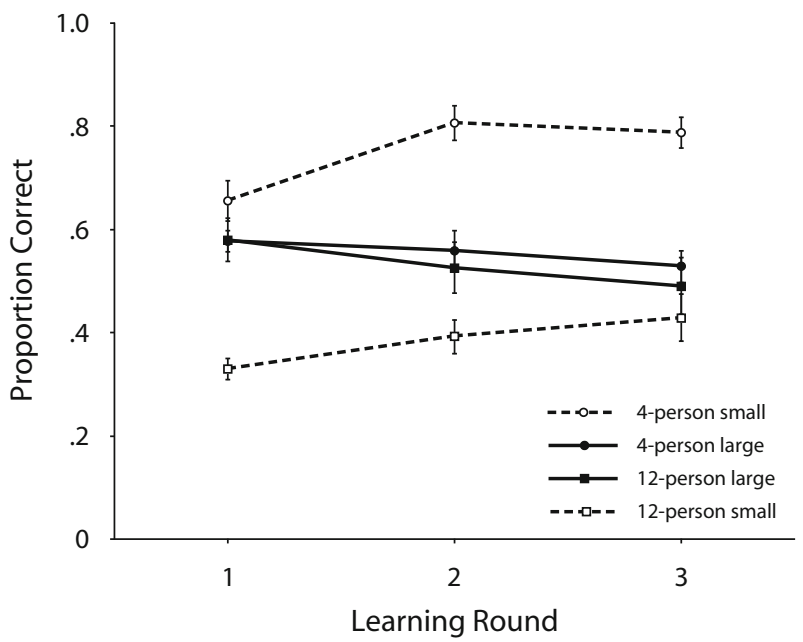

Figure 1. Proportion of correct responses during learning as a function of test condition, set-size group, and learning round in Experiment 1. Bars represent standard errors of the mean.

interaction of set-size group and test condition was significant $\left[F(1,44)=4.47, M S_{\mathrm{e}}=.021, p=.04\right]$. Initiation times were slowest when participants in effect had to select among three exemplars for a given fact category, which was only the case for the 12-person small-set group.

\section{Test}

Accuracy. Accuracy was better for the small-set than for the large-set group $\left[F(1,44)=40.56, M S_{\mathrm{e}}=.026, p<\right.$ $.01]$. Accuracy was also better for the 4-person than for the 12-person condition $\left[F(1,44)=11.05, M S_{\mathrm{e}}=.026\right.$, $p<.01]$. However, the advantage for the small-set group was larger in the 4-person than in the 12-person condition (Table 2); the interaction of set-size group and test condition was significant $\left[F(1,44)=9.62, M S_{\mathrm{e}}=.026, p<\right.$ .01]. By a Bonferroni post hoc comparison, the advantage

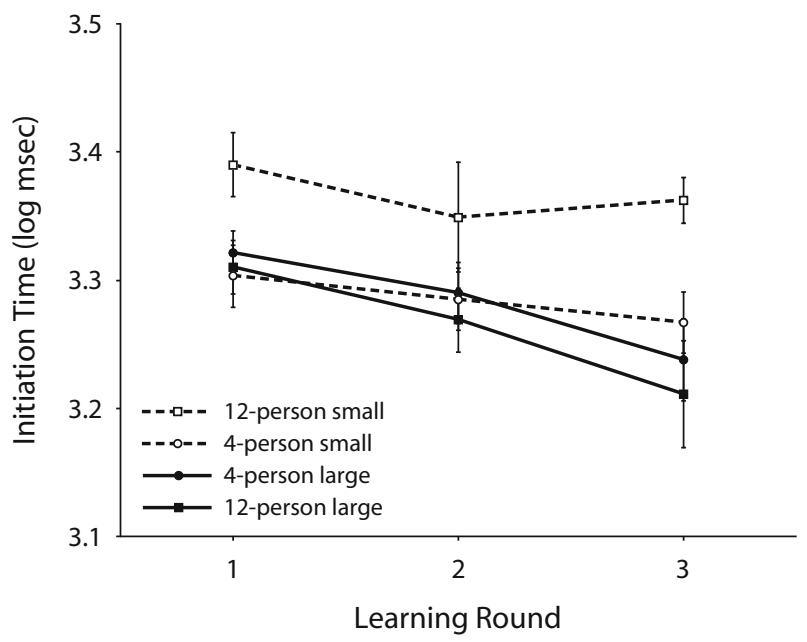

Figure 2. Initiation time (in $\log \mathrm{msec}$ ) during learning as a function of test condition, set-size group, and learning round in Experiment 1. Bars represent standard errors of the mean. for the small-set group was significant for both test conditions. This interaction also indicates that the advantage for the 4-person condition was found only in the small-set group, where the difference applied to learning as well as testing. This pattern of results is consistent with the predictions made by the mental model account.

Initiation time. There were no effects on initiation times at test.

\section{Summary}

During learning, the 4-person condition was more accurate than the 12-person condition. In addition, the small-set group showed higher accuracy than the large-set group in the 4-person condition, but the opposite pattern was found in the 12-person condition. Thus, performance was better when participants learned about a smaller number of individuals, holding number of facts per person constant at 12 , but was worse when learning a smaller number of facts, holding number of individuals constant at 12 . Improvement in accuracy across rounds was found for the small-set group, but a decline in accuracy across rounds was found for the large-set group. During testing, accuracy was higher for the small-set than for the large-set group and was higher for the 4-person than for the 12-person condition. The difference between the 4-person and the 12person conditions was only evident for the small-set group, for whom the distinction applied during learning as well as testing. These results are consistent with the predictions based on the mental model account rather than those based on the propositional network account. They are also consistent with an earlier study by Yntema and Mueser (1960) in which participants had to keep track of the present state of object attributes. Performance was lower for conditions involving one attribute of different objects than those involving different attributes of the same object.

\section{EXPERIMENT 2}

In Experiment 1, for the 4-person small-set group, participants were presented with a total of 12 facts about each of 4 unfamiliar individuals, whereas in the 12-person small-set group, participants were presented with only 4 facts about each of 12 unfamiliar individuals. Each time participants were presented with a new fact about an unfamiliar individual, they might have reactivated the previously learned facts about that individual. Participants in the 4-person small-set group were shown the names of each individual in their learning set more often than were participants in the 12-person small-set group, and were thus afforded more rehearsal opportunities. If participants did use this strategy, then the advantage for the 4-person small-set group relative to the 12-person smallset group is attributable entirely to additional rehearsal. Another potential problem with interpreting the results of Experiment 1 is that it is uncertain whether participants organized material by person or by fact category. If participants organized material by fact category, then the results of Experiment 1 are consistent with a propositional network account. 
Table 2

Summary of Test Results in Experiments 1 and 2

\begin{tabular}{|c|c|c|c|c|}
\hline \multirow[b]{2}{*}{ Set } & \multicolumn{2}{|c|}{ Accuracy } & \multicolumn{2}{|c|}{$\begin{array}{l}\text { Initiation Time } \\
\quad(\log \mathrm{msec})\end{array}$} \\
\hline & $M$ & SEM & $M$ & SEM \\
\hline \multicolumn{5}{|c|}{ Experiment 1} \\
\hline \multicolumn{5}{|l|}{ Large } \\
\hline 4-person & .132 & .035 & 3.427 & 0.038 \\
\hline 12-person & .122 & .040 & 3.405 & 0.040 \\
\hline \multicolumn{5}{|l|}{ Small } \\
\hline 4-person & .575 & .064 & 3.370 & 0.028 \\
\hline 12-person & .274 & .044 & 3.427 & 0.022 \\
\hline \multicolumn{5}{|c|}{ Experiment 2} \\
\hline \multicolumn{5}{|l|}{ Small } \\
\hline 4-person & .613 & .076 & 3.356 & 0.026 \\
\hline 12 -person & .132 & .028 & 3.460 & 0.036 \\
\hline
\end{tabular}

Experiment 2 was conducted to address these two issues. Because the primary interest lies with the small-set group, the large-set group was eliminated. In Experiment 2, participants in both the 4-person and the 12-person conditions were shown 12 facts about 12 unfamiliar individuals. However, for both conditions, only 48 of these facts were substantive and required learning. As in Experiment 1, the substantive facts were comprised of 12 facts describing 4 individuals in the 4-person condition and 4 facts describing 12 individuals in the 12-person condition. Thus, participants in both conditions were exposed to all 12 of the names of the individuals in their respective learning sets and all 12 of the fact categories an equal number of times; therefore, the two conditions were equated in the rehearsal opportunities.

To ensure that participants formed person-based mental models, explicit instructions were given to participants to organize facts by person; such a manipulation was effectively employed by Sohn et al. (2004).

\section{Method}

\section{Participants}

Twenty-four University of Colorado undergraduates participated. All were native English speakers.

\section{Design}

The design of the learning phase was a $2 \times 3$ mixed factorial, with the first factor manipulated between subjects. The first variable was test condition. In the 12-person condition, participants were tested on 4 facts about each of 12 individuals, and in the 4-person condition, participants were tested on 12 facts about each of 4 individuals. The remaining factor was learning round (1-3).

The design of the test phase included only the variable test condition. Both proportion of correct responses and time to initiate correct responses were analyzed.

\section{Materials}

The same materials were used as in Experiment 1, except that in the 4-person condition the fact-category exemplars were replaced with seven X's for all 12 facts about 8 individuals, whereas in the 12-person condition the same was true for 8 facts about each of the 12 individuals.

\section{Procedure}

The same procedure was used as in Experiment 1 with two exceptions. First, participants were explicitly instructed to organize facts by person ("associate each fact with each person"). Second, participants were told that some facts would be uninformative and that the fact category exemplar would be a series of Xs. They were told to respond with Xs when tested on those facts.

\section{Results}

\section{Learning}

Accuracy. Accuracy was near the ceiling for both the 4-person (.913) and the 12-person condition (.911) across the three learning rounds, presumably because only four of the facts learned in a given block were informative. Hence, there were no significant effects.

Initiation time. The analysis of initiation time revealed a main effect of learning round $\left[F(2,44)=34.07, M S_{\mathrm{e}}=\right.$ $.001, p<.01$ ], because initiation time decreased monotonically across learning rounds (Figure 3 ).

\section{Test}

Accuracy. Performance at test was over four times as high for the 4-person as for the 12-person condition $\left[F(1,22)=35.49, M S_{\mathrm{e}}=.039, p<.01\right]$. Accuracy for the 12-person condition was lower in Experiment 2 than in Experiment 1 (Table 2) presumably because the ease of learning only 4 , rather than 12 , informative facts during learning did not promote long-term retention.

Initiation time. Initiation time showed a main effect of test condition, with responses significantly quicker for the 4-person than for the 12-person condition $[F(1,22)=$ $\left.5.59, M S_{\mathrm{e}}=.012, p=.03\right]$.

\section{Summary}

Even though name exposure, and hence rehearsal opportunities, were equated during learning and even though the person focus was strengthened through instructions, we replicated in Experiment 2 the finding from Experiment 1 that accuracy at test was higher for the 4-person than for the 12-person condition. Furthermore, initiation time was faster for the 4-person than for the 12-person condition. Thus, there was an advantage at test for learning about a

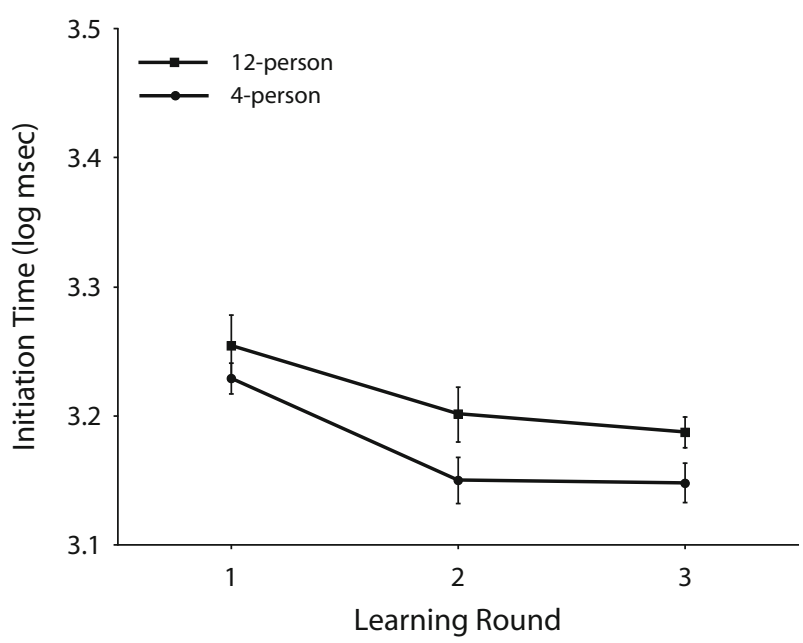

Figure 3. Initiation time (in $\log \mathrm{msec}$ ) during learning as a function of test condition and learning round in Experiment 2. Bars represent standard errors of the mean. 
smaller number of individuals, even when controlling for name exposure. These findings are in accordance with the predictions based on the mental model account and not with those based on the propositional network account.

\section{DISCUSSION}

The present study was conducted to assess the impact of memory set size and information structure on learning and retention. During the learning phase of Experiment 1, there was an advantage in accuracy for the 4-person smallset group relative to a large-set control group, whereas there was a disadvantage for the 12-person small-set group relative to a large-set control group. These results seem more consistent with the mental model account when considering each block of 12 sentences. For the 4-person condition, for a given block in the small-set group 3 facts were presented about each of 4 individuals, whereas in the large-set group one fact was presented about each of 12 individuals. Thus, for the first 4 blocks, relative to the smallset group, the large-set group was susceptible to higher levels of intermodel interference and lower levels of intramodel interference. The large-set group then completed an additional 8 blocks of learning, during which more facts were incorporated into each mental model, resulting in higher levels of intramodel interference. Therefore, the large-set group was always susceptible to higher levels of intermodel interference, and given the assumption of the mental model account that intermodel interference is larger than intramodel interference, the disadvantage for the large-set group follows from mental model theory.

The pattern of results during learning for the 12-person condition of Experiment 1 is less clear. For the 12-person condition, for a given block in both the small-set and large-set groups, one fact was presented about each of 12 individuals. Thus, for the first 4 blocks, the large-set and small-set groups were susceptible to equal amounts of intermodel and intramodel interference. The large-set group then completed an additional 8 blocks of learning, during which more facts were incorporated into each mental model, thereby resulting in increasing levels of intramodel interference. A mental model account would seem to predict better performance for the small-set relative to the large-set group, which was not the pattern observed. However, another difference between the small-set and largeset groups is that each fact category was used three times within each block in the small-set group, but only once in the large-set group. In terms of mental model theory, it might be the case that when the same fact category is used three times within each block it is less likely that the correct item will be incorporated into the appropriate mental model. In such a situation, the participant must select from among three exemplars for a given fact category so that the given exemplar would be less distinctive (e.g., Eysenck, 1979); in contrast, no such selection would be required when each fact category is used only once in a given block. This explanation involving an extra selection process is consistent with the relatively slow initiation time found for the 12-person small-set group. Regardless, the results for learning are clearly inconsistent with a propositional network account, because that account would predict best performance for the 12-person small-set group, which was instead the group with the worst performance.

The results of the test phase of both Experiments 1 and 2 are even more consistent than are those of the learning phase with a mental model account. For information that is already in memory, the mental model account predicts an advantage for both of the small-set groups when compared with large-set control groups, with the advantage larger in the 4-person than in the 12-person condition. This was exactly the pattern found in Experiment 1 for accuracy. Experiment 2 confirmed the advantage for the 4-person condition relative to the 12-person condition in the small-set group for initiation time as well as for accuracy, even though the rehearsal opportunities were equated in the two conditions because all individuals were shown equally often.

Thus, one major conclusion is that a mental model account provides a better description of memory representations and the retrieval process in the present paradigm. This conclusion is opposite to that reached by Sohn et al. (2004) who employed the fan-effect paradigm. The logic underlying their comparisons differed to a large extent from that employed in the present study. Specifically, they compared the magnitude of the fan effect for focused and nonfocused dimensions. Although they did find that the fan effect for the focused dimension was larger than that for the nonfocused dimension, as predicted by the propositional network account, they found large fan effects for both dimensions. Furthermore, for the conditions of the Sohn et al. study most similar to the ones in the present study (accuracy with the person focus condition), the results are inconclusive.

More generally, the present findings imply that if memory set size is too large, then individuals might not be able to learn a sufficient amount of the information presented to them. Under the assumption that memory set size does not exceed the individual's capability, information that is structured in a way such that it can be integrated into a small number of representations will be recalled better than information structured into a larger number of representations.

\section{AUTHOR NOTE}

This research was supported by ARI Contract DASW01-03-0002 and ARO Grant W9112NF-05-1-0153. We thank Lyle Bourne, Douglas Nelson, and Gabriel Radvansky for useful comments about this research. Address correspondence to J. A. Kole, Department of Psychology, 345 UCB, Muenzinger Building, University of Colorado, Boulder, CO 80309-0345 (e-mail: james.kole@ colorado.edu).

\section{REFERENCES}

Anderson, J. R. (1974). Retrieval of propositional information from long-term memory. Cognitive Psychology, 6, 451-474.

ANDERSON, J. R. (1983). The architecture of cognition. Cambridge, MA: Harvard University Press.

EysEnCK, M. W. (1979). Depth, elaboration, and distinctiveness. In L. S. Cermak \& F. I. M. Craik (Eds.), Levels of processing in human memory (pp. 89-118). Hillsdale, NJ: Erlbaum.

Johnson-LAIRD, P. N. (1983). Mental models: Towards a cognitive science of language, inference, and consciousness. Cambridge, MA: Harvard University Press.

Kole, J. A., \& Healy, A. F. (2007). Using prior knowledge to minimize 
interference when learning large amounts of information. Memory \& Cognition, 35, 124-137.

RADVANSKY, G. A. (2005). Situation models, propositions, and the fan effect. Psychonomic Bulletin \& Review, 12, 478-483.

RadvansKY, G. A., \& ZaCKS, R. T. (1991). Mental models and the fan effect. Journal of Experimental Psychology: Learning, Memory, \& Cognition, 17, 940-953.

Sohn, M.-H., Anderson, J. R., Reder, L. M., \& Goode, A. (2004). Differential fan effect and attentional focus. Psychonomic Bulletin \& Review, 11, 729-734.
VAN DIJK, T. A., \& KINTSCH, W. (1983). Strategies in discourse comprehension. New York: Academic Press.

Van Overschelde, J. P., \& Healy, A. F. (2001). Learning of nondomain facts in high- and low-knowledge domains. Journal of Experimental Psychology: Learning, Memory, \& Cognition, 27, 1160-1171.

WARD, G. (2002). A recency-based account of the list length effect in free recall. Memory \& Cognition, 30, 885-892.

Yntema, D. B., \& Mueser, G. E. (1960). Remembering the present states of a number of variables. Journal of Experimental Psychology, 60, 18-22.

APPENDIX

Facts Used in the Experiments, Organized by Fact Category

\begin{tabular}{|c|c|c|c|c|c|c|}
\hline Names & Verb Phrases & Astrological Signs & Authors & Cars & Collectibles & Dogs \\
\hline B. J. Crosby & astrological sign is & Scorpio & Faulkner & Honda & antiques & spaniel \\
\hline Barbara Fontana & likes books by & Libra & King & Nissan & dolls & retriever \\
\hline Brian Burke & drives a & Aries & Steinbeck & Saab & pictures & dachshund \\
\hline Gina Ferrall & collects & Sagittarius & Poe & Cadillac & spoons & bulldog \\
\hline Kent Steffes & has a pet & Aquarius & Voltaire & Porsche & shoes & labrador \\
\hline Linda Hanley & drinks & Cancer & Hemingway & $B M W$ & books & collie \\
\hline Michael Siberry & likes to eat & Taurus & Shakespeare & Toyota & cars & rottweiler \\
\hline Mike Whitmarsh & likes the month of & Pisces & Dante & Chevy & stamps & poodle \\
\hline Nancy Reno & watched the movie & Virgo & Austen & $V W$ & cards & mutt \\
\hline Roberto Lopez & listens to & & Salinger & Ford & money & dalmation \\
\hline Stephanie Bennet & likes to play & Gemini & Koontz & Mercedes & coins & huskie \\
\hline Yvette Freeman & watches the TV show & Capricorn & Grisham & Jeep & rocks & shepherd \\
\hline Drinks & Foods & Months & Movies & Music & Sports & TV Programs \\
\hline milk & fish & Augu: & Trainspotting & country & softball & CSI \\
\hline tea & burgers & Februa & Goodfellas & reggae & soccer & Seinfeld \\
\hline juice & bread & September & Contact & rap & hockey & Alias \\
\hline margaritas & fondue & April & Poltergeist & hiphop & basketball & ER \\
\hline Pepsi & American & March & Blade & alternative & rugby & Southpark \\
\hline Sprite & chicken & June & Scream & oldies & baseball & Friends \\
\hline Coke & Chinese & May & Armageddon & classical & volleyball & Oprah \\
\hline beer & pizza & November & Jaws & ska & pool & Osbournes \\
\hline lemonade & vegetables & October & Spiderman & techno & football & Cheers \\
\hline wine & Mexican & January & Speed & jazz & golf & Frasier \\
\hline coffee & fruit & July & Terminator & pop & lacrosse & MASH \\
\hline water & Italian & December & Titanic & rock & tennis & Simpsons \\
\hline
\end{tabular}

Note-Boldface indicates facts tested in the 4-person condition, and italics indicate facts tested in the 12-person condition.

(Manuscript received September 12, 2006;

revision accepted for publication October 17, 2006.) 